\title{
Screening the effect of four ultrasound- assisted extraction parameters on hesperidin and phenolic acid content of aqueous citrus pomace extracts
}

Konstantinos Papoutsis, Penta Pristijono, John B. Golding, Costas E. Stathopoulos, Michael C. Bowyer, Christopher J. Scarlett and Quan V. Vuong

This is the accepted manuscript (C) 2017, Elsevier Licensed under the Creative Commons AttributionNonCommercial-NoDerivatives 4.0 International: http://creativecommons.org/licenses/by-nc-nd/4.0/

\section{(cc) $\mathrm{E} Y \mathrm{Y}-\mathrm{No}-\mathrm{ND}$}

The published article is available from doi: https://doi.org/10.1016/j.fbio.2017.11.001 
Screening the effect of four ultrasound-assisted extraction parameters on hesperidin and phenolic acid content of aqueous citrus pomace extracts

Running Title: Screening the effect of four ultrasound-assisted extraction parameters (1)

Konstantinos Papoutsis ${ }^{\mathrm{a},{ }^{*}}$, Penta Pristijono $^{\mathrm{a}}$, John B. Golding ${ }^{\mathrm{a}, \mathrm{b}}$, Costas E. Stathopoulos ${ }^{\mathrm{c}}$, Michael C. Bowyer ${ }^{\mathrm{a}}$, Christopher J. Scarlett ${ }^{\mathrm{a}}$, Quan V. Vuong ${ }^{\mathrm{a}}$ (1)

${ }^{a}$ School of Environmental and Life Sciences, The University of Newcastle PO Box 127 Ourimbah, NSW 2258, Australia

${ }^{\mathrm{b}}$ NSW Department of Primary Industries, Locked Bag 26 Gosford, NSW 2250, Australia

${ }^{c}$ Division of Food and Drink School of Science, Engineering and Technology University of Abertay Dundee DD1 1HG UK

\section{*Corresponding author: PhD Candidate, Konstantinos Papoutsis; e-mail addresses:}

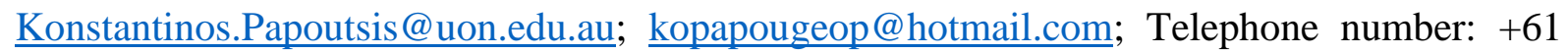
0424259273; Fax number: +61 024921 7949; Nutrition Food \& Health Research Group, School of Environmental and Life Sciences, University of Newcastle, Brush Rd, Ourimbah, NSW 2258, Australia. 


\section{Abstract}

Polyphenols of citrus by-products, due to their antioxidant and antimicrobial activities, could be valorized by pharmaceutical and food industries, adding a value to the citrus processing companies. A number of studies have investigated the effect of ultrasound-assisted extraction (UAE) conditions on the recovery of phenolics derived from citrus waste using both organic solvents or mixed aqueous solvent systems. To maximize efficiency, UAE conditions should be tailored to the physical parameters of the solvent(s) employed. The aim of this study was to investigate the effect of four UAE parameters: particle size $(1.40-2.80 \mathrm{~mm})$, extraction time (10-60 min), extraction temperature $\left(23-50{ }^{\circ} \mathrm{C}\right)$ and ultrasonic power $(150-250 \mathrm{~W})$ on the simultaneous recovery of $p$-coumaric acid, caffeic acid, chlorogenic acid, and hesperidin from citrus waste using pure water as a solvent. High-performance liquid chromatography (HPLC) was employed for the identification and quantification of the cited compounds. Particle size was determined to be an important parameter affecting compound recovery, with the exception of chlorogenic acid. A particle size of $1.40 \mathrm{~mm}$ resulted in the highest recovery of $p$-coumaric and caffeic acids $(0.25$ and $0.58 \mathrm{mg} / \mathrm{g}$, respectively), while higher hesperidin yields were achieved from the particle sizes of 2.00 and $1.40 \mathrm{~mm}(6.44$ and $6.27 \mathrm{mg} / \mathrm{g}$, respectively). Extraction temperature significantly affected only the recovery of the flavanone glycoside $(P<0.05)$. As the extraction temperature increased from 30 to $50{ }^{\circ} \mathrm{C}$ the recovery of hesperidin increased from 6.59 to $7.84 \mathrm{mg} / \mathrm{g}$, respectively. Neither extraction time nor ultrasonic power significantly affected the recovery of any individual phenolic compound.

Keywords: sustainable extraction, particle size, phenolic acids, flavanone, citrus waste. 


\section{Introduction}

Lemons (Citrus limon L.) are widely grown around the world and are known for their nutritional value. In 2013/14, lemon and lime production exceeded 13 million tonnes where more than $14 \%$ of this production was processed (FAO, 2016). During lemon processing, a large amount of solid waste, primarily composed of the peel (flavedo and albedo) and seeds, is generated. Citrus peel is comprised of a wide variety of organic compounds including polyphenols, vitamins, sugars, organic acids, fibers and oils (Putnik et al., 2017; Sharma et al., 2017).

Polyphenols are the most abundant secondary metabolites synthesized by fruits and vegetables, and are responsible for their organoleptic properties (Dai and Mumper, 2010). Citrus peel contains quantities of flavonoids (flavanones, flavonols and flavones) and phenolic acids. Flavonoids are important bioactive compounds due to their antioxidant, anticancer, antifungal and antibacterial activities (Ortuño et al., 2006; Casquete et al., 2015; Sharma et al., 2017). Hesperidin is a flavanone glycoside found in lemon peel and has been reported to possess antibacterial, antifungal and anti-inflammatory properties (Garg et al., 2001). Phenolic acids, such as hydroxycinnamic and hydroxybenzoic acids, also present in lemon peel which have been linked to antioxidant, antifungal and antimicrobial activities (Wang et al., 2007; Shetty et al., 2016; Papoutsis et al., 2017).

Presently, peel derived from citrus processing is typically discarded as landfill, representing a cost and environmental liability to the industry. The opportunity to extract bioactives from peel waste for use in foods or pharmaceuticals using economic, environmentally sustainable practices products, therefore, represents an attractive proposition to the citrus industry.

Extraction must be undertaken to liberate phenolic compounds from lemon peel and appropriate extraction conditions must be identified in order to maximize their recovery yields 
(Putnik et al., 2017). Methanol, ethanol or corresponding aqueous mixtures of these solvents are typically employed for the recovery of polyphenols from citrus pomace (Abad-García et al., 2007; Lou et al., 2016). Despite their efficiency, the cost of these solvents is high. Safety and toxicity concerns also exist over the industrial scale use of alcohols, leading to water being the preferred solvent for high volume extraction. Consequently, techniques to improve the efficiency of aqueous extraction remains a priority for researchers.

Although ultrasound-assisted extraction (UAE) has been previously identified as an efficient extraction technique (Roselló-Soto et al., 2015), undesirable UAE conditions may lead to a significant degradation of phenolic compounds (Dahmoune et al., 2013; Babazadeh et al., 2017). Solvent type, extraction time, extraction temperature, particle size of the sample, ultrasonic power and frequency are parameters that may affect the recovery of phenolic compounds (Chemat et al., 2017). Khan et al. (2010) reported that sample particle size significantly affected UAE yield efficiency of total phenolic compounds from orange peels, while Ma et al. (2009) identified temperature as a variable affecting the extraction yields of phenolic acids from Citrus unshiu Marc peels.

To date, most of the studies that have investigated the effect of different UAE parameters (such as ultrasonic power and frequency, extraction time and temperature) on the recovery of individual phenolic compounds from citrus have employed either pure organic solvents or mixed aqueous solvent systems (Ma et al., 2008a; Ma et al., 2008b; Ma et al., 2009). Chemat et al. (2017) recently reported that UAE conditions should be selected according to the physical parameters of the solvents that are employed. Moreover, to date, the effect of particle size of the sample on the recovery of individual phenolic compounds from citrus waste has not been reported. The aim of this study was to investigate the effect of four UAE parameters, including particle size of sample, extraction time, extraction temperature and ultrasonic power on the simultaneous recovery of hesperidin, $p$-coumaric acid, caffeic acid, and chlorogenic acid 
from lemon pomace, using distilled water as the extracting solvent. High-performance liquid chromatography was performed for the identification and quantification of the individual phenolic compounds.

\section{Materials and methods}

\subsection{Chemicals}

All chemicals used in this study were of analytical grade. Folin-Ciocalteu phenol reagent, sodium carbonate $\left(\mathrm{Na}_{2} \mathrm{CO}_{3}\right)$ anhydrous, sodium nitrite $\left(\mathrm{NaNO}_{2}\right)$, gallic acid, catechin, hesperidin, $p$-coumaric acid, chlorogenic acid, caffeic acid, formic acid, copper (II) chloride $\left(\mathrm{CuCl}_{2}\right), \quad$ ammonium acetate $\quad\left(\mathrm{NH}_{4} \mathrm{Ac}\right), \quad$ neocuproine, $\quad( \pm)$-6-hydroxy-2,5,7,8tetramethylchromane-2-carboxylic acid (Trolox), 2,2-diphenyl-1-picrylhydrazyl (DPPH) were purchased from Sigma-Aldrich Pty Ltd (Castle Hill, Sydney, Australia). Aluminium chloride $\left(\mathrm{Al}_{2} \mathrm{Cl}_{3} \cdot 6 \mathrm{H}_{2} \mathrm{O}\right)$ was obtained from J. T. Baker Chem. Co. (Zedelgem, Belgium). Sodium hydroxide $(\mathrm{NaOH})$ was purchased from Ajax Chem. (NSW, Australia). Methanol, ethanol and acetonitrile were purchased from Merck (Darmstadt, Germany).

\subsection{Materials}

Lemon (Citrus limon L.) waste, including peel, membranes and seeds, was kindly provided by the Eastcoast company (Kulnura, NSW, Australia). Pomace was collected the same day of lemon juice production and was immediately transferred to the laboratory $\left(20{ }^{\circ} \mathrm{C} \pm 0.5\right.$ ${ }^{\circ} \mathrm{C}$ ). After seed removal, the remaining pomace with a moisture content of $85.1 \% \pm 1.2 \%$ (mean \pm standard deviation), was stored at $-18{ }^{\circ} \mathrm{C}$ until use, to prevent polyphenol degradation. Low temperatures tend to decrease the activity of polyphenol oxidase (PPO) the enzyme responsible for polyphenol oxidation (Nguyen et al., 2003). Citrus waste was dried by freeze drying (FD3 freeze dryer; Thomas Australia Pty. Ltd., Seven Hills, Australia) as described by Papoutsis et 
al. (2017). The dried pomace was ground using a commercial blender (Waring 2-speed blender, John Morris Scientific, Chatswood, Australia), with the resulting powder then sized and separated using three steel mesh sieves (1.40, 2.00, $2.80 \mathrm{~mm}$ ) (EFL 2000; Endecotts Ltd., London, England). The ground lemon waste was then sealed in a container and stored at -18 ${ }^{\circ} \mathrm{C}$ until required. The water activity $\left(\mathrm{a}_{\mathrm{w}}\right)$ of the dried lemon pomace was determined to be 0.19 \pm 0.01 (mean \pm standard deviation) at $24.3{ }^{\circ} \mathrm{C}$ and the residual moisture content was $7.36 \% \pm$ $0.51 \%$ (mean \pm standard deviation).

\subsection{Ultrasound-assisted extraction (UAE)}

A 20 L ultrasonic bath (Soniclean Pty Ltd., Thebarton, Australia) operating at a frequency of $43 \pm 2 \mathrm{kHz}$ was employed for pomace extraction. The effects of four individual parameters: i) particle size of sample $(1.40,2.00$ and $2.80 \mathrm{~mm})$, ii) extraction time $(10,20,30,40,50$ and 60 min), iii) extraction temperature (ambient $\left(23^{\circ} \mathrm{C}\right), 30,40$ and $\left.50^{\circ} \mathrm{C}\right)$, and iv) ultrasonic power (150, 200 and $250 \mathrm{~W})$ on the recovery of hesperidin, $p$-coumaric acid, caffeic acid, chlorogenic acid, total phenolic content, total flavonoid content, as well as antioxidant capacity of lemon pomace aqueous extracts were investigated. In all experiments, a sample-to-solvent ratio of 1 $\mathrm{g} / 100 \mathrm{~mL}$ was used (Papoutsis et al., 2016). Initially, the effect of particle size was investigated and the particle size of 1.40 was selected for the following experiments, since it resulted in the highest recovery of the most of the parameters that were examined. Every time that one parameter was examined, the others maintained constant. The constant values for the extraction temperature, extraction time and ultrasonic power were $30^{\circ} \mathrm{C}, 20 \mathrm{~min}$ and $150 \mathrm{~W}$, respectively. The experimental design of the experiment can be seen in Fig. 1. 


\subsection{Phytochemical analysis}

\subsubsection{Identification and quantification of individual phenolic compounds}

The identification and quantification of hesperidin, $p$-coumaric acid, chlorogenic acid, and caffeic acid was performed using high-performance liquid chromatography (HPLC) (Shimadzu LC-20AD, Rydalmere, NSW, Australia). Both standards and samples were prefiltered through a $0.45 \mu \mathrm{m}$ nylon filter prior to analysis. $\mathrm{A} \mathrm{C}_{18}$ reversed-phase column (Gemini 110A 5 m, $150 \times 4.6$ mm Phenomenex Australia Pty., Ltd., Lane Cove, NSW, Australia) fitted with a guard column (Gemini $\mathrm{C}_{18}, 4 \times 3.0 \mathrm{~mm}$ ) was used for the separation. The injection volume for samples and standards was $50 \mu \mathrm{L}$. The column temperature was maintained at 30 ${ }^{\circ} \mathrm{C}$ using an oven (Shimadzu CTO-20AC, Rydalmere, NSW, Australia). A photodiode array (PDA) detector (Shimadzu SPD-M20A, Rydalmere, NSW, Australia) was employed for sample detection (250-380 nm). The mobile phase for separation was as follows; water: acetonitrile: formic acid, 95:4:1 (v:v:v) (Mobile Phase A) and 100\% (v/v) acetonitrile (Mobile Phase B). The flow rate of the solvents was $1 \mathrm{~mL} / \mathrm{min}$ using the following gradient elution: $0 \mathrm{~min} 5 \% \mathrm{~B}$; $15 \mathrm{~min}, 20 \% \mathrm{~B} ; 35 \mathrm{~min}, 100 \% \mathrm{~B} ; 40 \mathrm{~min}, 5 \% \mathrm{~B} ; 50 \mathrm{~min}, 50 \% \mathrm{~B}$. Analysis ceased after $60 \mathrm{~min}$. The system was re-equilibrated between runs for 10 min using $5 \% \mathrm{~B}$.

The quantification of hesperidin, chlorogenic acid, caffeic acid and $p$-coumaric acid contents were calculated from the peak area recorded at $\lambda=280 \mathrm{~nm}$ by the external standard method using calibration curves $\left(\mathrm{R}^{2}=0.9995,0.9932,0.9978\right.$ and 0.9999 , respectively). Hesperidin, chlorogenic acid, caffeic acid and $p$-coumaric acid standards were prepared by dissolving standard compounds in methanol at a concentration of $200 \mu \mathrm{g} / \mathrm{mL}$. Their concentrations were expressed as $\mathrm{mg} / \mathrm{g}$. 


\subsubsection{Total phenolic content (TPC)}

The TPC was measured according to Škerget et al. (2005). Gallic acid was used as a standard to build the calibration curve $\left(\mathrm{R}^{2}=0.9923\right)$ and the results were expressed as $\mathrm{mg}$ of gallic acid equivalents per g (mg GAE/g).

\subsubsection{Total flavonoid content (TF)}

The TF was determined according to Zhishen et al. (1999). Catechin was used as a standard to build the calibration curve $\left(\mathrm{R}^{2}=0.9928\right)$ and the results were expressed as $\mathrm{mg}$ of catechin equivalents per $\mathrm{g}(\mathrm{mg} \mathrm{CE} / \mathrm{g})$.

\subsubsection{Antioxidant capacity}

Cupric Reducing Antioxidant Capacity (CUPRAC) was determined according to Apak et al. (2004). Trolox was used as a standard to build the calibration curve $\left(\mathrm{R}^{2}=0.9900\right)$ and the results were expressed as mg Trolox equivalents per $\mathrm{g}$ (mg TE/g). DPPH radical scavenging capacity was determined according to Thaipong et al. (2006). Trolox was used as a standard to build the calibration curve $\left(\mathrm{R}^{2}=0.9980\right)$ and the results were expressed as $\mathrm{mg}$ Trolox equivalents per $\mathrm{g}$ (mg TE/g).

\subsection{Scanning electron microscopy (SEM)}

SEM was employed for observing the morphology of the different particle sizes of lemon pomace residues using a Phillips XL 30 microscope. Samples were gold coated ( $3 \mathrm{~min}$ ) before the images were taken using a secondary electron detector. 


\subsection{Statistical analysis}

The effect of independent variables (particle size of sample, extraction time, extraction temperature and ultrasonic power) on individual phenolic compounds, TPC, TF, CUPRAC and DPPH was investigated by employing one-way ANOVA and Tukey's test, using SPSS statistical software (version 23, IBM, Crop., NY, USA) at $P<0.05$. Each extraction run and analysis were performed in triplicate.

\section{Results and Discussion}

3.1. Effect of particle size on hesperidin, chlorogenic acid, caffeic acid, and $p$-coumaric acid contents

The effect of particle size on the recovery of chlorogenic acid, caffeic acid, $p$-coumaric acid, and hesperidin is shown in Fig. 2A, B. As the particle size decreased from $2.80 \mathrm{~mm}$ to $1.40 \mathrm{~mm}$ the recovery of caffeic acid and $p$-coumaric acid significantly increased from $(0.52$ and $0.12 \mathrm{mg} / \mathrm{g}$, respectively) to $(0.58$, and $0.25 \mathrm{mg} / \mathrm{g}$, respectively $)(P<0.05)$. In case of hesperidin, greater recovery was achieved from the particle sizes of 2.00 and $1.40 \mathrm{~mm}(6.44$ and $6.27 \mathrm{mg} / \mathrm{g}$, respectively). However, particle size had no influence on the recovery of chlorogenic acid $(P<0.05)$ (Fig. 2A). Prior to extraction, particles from each sieve range were examined using scanning electron microscopy. The images (Fig. 3) reveal that the surface area in contact with the solvent significantly increased as the particle size diminished from 2.80 to $1.40 \mathrm{~mm}$, facilitating greater penetration of the solvent into the plant tissue, which promotes greater mass transfer from the solid matrix into the liquid. Phenolic compounds of citrus pomace can be found either sequestered into the vacuole or bound onto the cell matrix (Shahidi and Yeo, 2016). Decreasing the particle size under UAE conditions, the sample area exposed to ultrasonic radiation increases (Fig. 3), which may lead to an increased breakdown of cellular material and vacuole, which facilitates greater penetration of the solvent into the plant matrix, 
leading to higher diffusion rates of polyphenols into the solvent (Roselló-Soto et al., 2015). Simultaneously, cavitation phenomena may facilitate in the release of the phenolic compounds which are bound onto the cell walls. These results are in accordance with Lee et al. (2010) who mentioned that the extraction yields of nobiletin and tangeretin increased as the particle size of orange peel decreased from 0.75 to $0.188 \mathrm{~mm}$ under supercritical fluid extraction $\left(\mathrm{CO}_{2}\right)$. As a consequence of these findings, a particle size of $1.40 \mathrm{~mm}$ was selected for the assessment of the other experimental variables affecting extraction efficiency.

3.2. Effect of extraction time on hesperidin, chlorogenic acid, caffeic acid, and $p$-coumaric acid contents

The effect of extraction time on the recovery of chlorogenic acid, caffeic acid, $p$ coumaric acid, and hesperidin is shown in Fig. 2C, D. Extraction time as a variable had no significant effect on the yields of hesperidin or the phenolic acids of lemon pomace under the extraction conditions applied (particle size $=1.40 \mathrm{~mm}$, power $=150 \mathrm{~W}$, temperature $=30{ }^{\circ} \mathrm{C}$ ) $(P<0.05)$. This finding was in contrast to recently reported findings by Hani et al. (2017) who identified a correlation between extraction efficiency and extraction time - albeit a modest one. It has been previously reported that lemon pomace is resistant to ultrasound energy when the extraction is carried out at ambient temperature (Dahmoune et al., 2013), suggesting a possible explanation for our findings. A slight, but non-significant rise in hesperidin yield was recorded by increasing extraction time from 20 to $40 \mathrm{~min}$ (from 6.22 to $6.67 \mathrm{mg} / \mathrm{g}$, respectively), after which the yield slightly declined. Although extraction time did not affect the recovery of phenolic acids, the maximum extraction yields of caffeic and chlorogenic acids were obtained when the UAE was performed for $40 \mathrm{~min}(0.56$ and $0.32 \mathrm{mg} / \mathrm{g}$, respectively) and then slightly declined, whereas the maximum $p$-coumaric acid yield was obtained when the UAE was performed for $60 \mathrm{~min}(0.25 \mathrm{mg} / \mathrm{g})$. These results indicated that prolong sonication times may 
lead to the formation of free radicals which may be scavenged by some phenolic compounds (Dahmoune et al., 2013). Ma et al. (2008b) reported that the content of hesperidin derived from penggan (Citrus reticulata) peel in methanol extracts significantly increased as the sonication time increased from 20 to $60 \mathrm{~min}$. Moreover, it has been previously mentioned that sonication time significantly affected the recovery of phenolic acids from citrus peels in a temperature dependent manner (Ma et al., 2009). These differences could be attributed to the variability of the cellular wall ultrastructure and composition between citrus species (Li et al., 2009), which is known to affect cavitation phenomena which occurs during UAE, as well as to the different physical parameters of the solvents and the different UAE conditions that were employed (Chemat et al., 2017).

3.3. Effect of extraction temperature on hesperidin, chlorogenic acid, caffeic acid, and $p$ coumaric acid contents

In UAE, temperature is considered as an important parameter influencing the recovery of bioactive compounds, since it directly affects both the physical parameters of the solvent employed and the effectiveness of sonication (Chemat et al., 2017).

Temperature had no significant effect on the recovery of phenolic acids but significantly affected the recovery of hesperidin from lemon pomace $(P<0.05)$ (Fig. 2E, F). Higher hesperidin yields were obtained as the temperature increased from 30 to $50{ }^{\circ} \mathrm{C}$ (from 6.59 to $7.84 \mathrm{mg} / \mathrm{g}$, respectively). Similar results have been reported for hesperidin recovery from Citrus reticulata peel using methanol as the extraction solvent under UAE (Ma et al., 2008b). Higher temperature in UAE may facilitate higher recovery of polyphenols by: i) affecting the physical properties of the solvent and by extension sonication effects, ii) enhancing the solubility of some phenolic compounds which increases mass transfer rate from the plant matrix into the solvent, and iii) diminishing the integrity of cellular structures by enhancing the activity of 
some enzymes (Ma et al., 2016). Under the UAE conditions applied in our study, the temperature did not affect the recovery of phenolic acids ( $p$-coumaric acid, caffeic acid, and chlorogenic acid). This is in contrast with the findings of Ma et al. (2009) who reported temperature to be a crucial factor influencing the recovery of phenolic acids from Citrus unshiu Marc peel. These differences could be due to the different physical parameters of the solvent, such as viscosity, surface tension, and vapor pressure, as well as the different operating conditions that were employed (Chemat et al., 2017).

3.4. Effect of ultrasonic power on hesperidin, chlorogenic acid, caffeic acid, and $p$ coumaric acid contents

Ultrasonic power had no significant effect on the recovery of phenolic acids, and hesperidin (Fig. 2G, H). A slight but non-significant rise in the recovery of hesperidin was found when the ultrasonic power increased from $150 \mathrm{~W}$ to $200 \mathrm{~W}$ (from 6.50 to $6.82 \mathrm{mg} / \mathrm{g}$ ) and then slightly declined $(6.65 \mathrm{mg} / \mathrm{g})$. These results are in accordance with the findings of Ma et al. (2008b) who reported that ultrasonic power exerted limited effect on the recovery of hesperidin from penggan (Citrus reticulata) peel. In contrast, studies by the same author found that the yield of phenolic acids extracted from satsuma mandarin peel increased with increasing ultrasonic power (from 3.2 to $56 \mathrm{~W}$ ) (Ma et al., 2008a). These differences could be attributed to the different UAE conditions, physical parameters of the solvents (viscosity and vapor pressure), as well as the composition of the plant matrix used in the studies. It has been previously reported that high-level ultrasonic power may degrade some polyphenols by inducing the production of free radicals within the solvent (Dahmoune et al., 2013). However, under the examined ultrasonic powers and conditions, the flavanone glycoside and the three phenolic acids were stable. 


\subsection{Effect of ultrasonic conditions on TPC, TF, and antioxidant capacity}

The effects of particle size, extraction time, extraction temperature and ultrasonic power on TPC, TF, and antioxidant capacity values are displayed in Tables 1 and 2 . Similarly to the individual phenolic compounds, particle size and extraction temperature significantly affected the recovery of TPC, TF and antioxidant capacity (Table 1,2). As the particle size decreased from 2.80 to $1.40 \mathrm{~mm}$, the TPC, TF, and antioxidant capacity values increased $(P<0.05)$. These results are in agreement with previous studies (Stamatopoulos et al., 2013; D’Alessandro et al., 2014). However, Khan et al. (2010) reported that under UAE, the total phenols extracted from orange peel slightly increased with increasing particle size (from 0.5 to $2.0 \mathrm{~cm}^{2}$ ). This result was attributed to the fact that during UAE, smaller particles remained at the air-solvent interface leading to limited exposure to ultrasonic waves and reduced extraction efficiency. However, this phenomenon was not noted in our study. Extraction temperatures of 40 and $50{ }^{\circ} \mathrm{C}$ resulted in higher TPC, TF, and antioxidant capacity values $(P<0.05)$ (Tables 1,2$)$. These results are in accordance with previous studies which mentioned temperature as an important parameter for the recovery of phenolic compounds from citrus peels (Ma et al., 2008c; Garcia-Castello et al., 2015). In conclusion, particle size of the sample and extraction temperature found to be the most important parameters affecting the values of TPC, TF and antioxidant capacity of lemon pomace aqueous extracts.

\section{Conclusions}

Hesperidin, $p$-coumaric, caffeic and chlorogenic acids due to their antioxidant and antimicrobial activities could be valorized by both pharmaceutical and food industries, adding a value to the citrus processing companies. The effects of four UAE parameters, including particle size of sample, extraction time, extraction temperature and ultrasonic power on the recovery of three phenolic acids and hesperidin from lemon pomace using water as a solvent, was examined. 
Particle size of the sample significantly affected the recovery of $p$-coumaric acid, caffeic acid, hesperidin, TPC, TF, and the antioxidant capacity. As the extraction temperature increased from 30 to $50{ }^{\circ} \mathrm{C}$, the recovery of hesperidin, TPC, TF and antioxidants measured by CUPRAC significantly increased, while extraction temperature had no effect on the recovery of phenolic acids ( $p$-coumaric acid, caffeic acid and chlorogenic acid) and antioxidant capacity measured by DPPH. Neither extraction time nor ultrasonic power had a significant effect on the recovery of polyphenols and antioxidants. With solvent considered to be an important parameter affecting the recovery of polyphenols under UAE, studies optimizing and scanning the interaction effects of different ultrasonic parameters on the recovery of individual phenolic compounds from citrus pomaces using water as a solvent should be examined, since most of the studies to date have focused on the use of organic solvents for the extraction.

\section{Acknowledgements}

This research was supported by the University of Newcastle and Australian Research Council (ARC) Training Centre for Food and Beverage Supply Chain Optimisation (IC140100032). NSW Department of Primary Industries is a partner organisation in the Training Centre. The authors would like to thank the staff of Electron Microscope and X-Ray Unit (EMX) for their support in SEM analysis. We also thank Mick Lentini at Eastcoast Food and Beverages for the supply of the lemon pomace.

\section{Conflict of interest statement}

The authors declare no conflict of interest. 
Funding This research was funded by the Scholarship that was provided by University of

350

351

352

353

354

355

356

357

358

359

360

361

362

363

364

365

366

367

368

369

370

371

372

373

374

375

376

377

378

379

380

381

382

383

384

385

386

387

388

389

390

391

Newcastle and Australian Research Council (ARC) Training Centre for Food and Beverage

Supply Chain Optimisation

\section{References}

Abad-García, B., Berrueta, L.A., López-Márquez, D.M., Crespo-Ferrer, I., Gallo, B., \& Vicente, F. (2007). Optimization and validation of a methodology based on solvent extraction and liquid chromatography for the simultaneous determination of several polyphenolic families in fruit juices. Journal of Chromatography A, 1154, 87-96.

Apak, R., Güçlü, K., Özyürek, M., \& Karademir, S.E. (2004). Novel total antioxidant capacity index for dietary polyphenols and vitamins $\mathrm{C}$ and $\mathrm{E}$, using their cupric ion reducing capability in the presence of neocuproine: CUPRAC Method. Journal of Agricultural and Food Chemistry, 52, 7970-7981.

Babazadeh, A., Taghvimi, A., Hamishehkar, H., \& Tabibiazar, M. (2017). Development of new ultrasonic-solvent assisted method for determination of trans-resveratrol from red grapes: Optimization, characterization, and antioxidant activity (ORAC assay). Food Bioscience, doi.org/10.1016/j.fbio.2017.08.003 (in press).

Casquete, R., Castro, S.M., Martín, A., Ruiz-Moyano, S., Saraiva, J.A., Córdoba, M.G., \& Teixeira, P. (2015). Evaluation of the effect of high pressure on total phenolic content, antioxidant and antimicrobial activity of citrus peels. Innovative Food Science and Emerging Technologies, 31, 37-44.

Chemat, F., Rombaut, N., Sicaire, A.G., Meullemiestre, A., Fabiano-Tixier, A.S., \& AbertVian, M. (2017). Ultrasound assisted extraction of food and natural products. Mechanisms, techniques, combinations, protocols and applications. A review. Ultrasonics Sonochemistry, 34, 540-560.

Dahmoune, F., Boulekbache, L., Moussi, K., Aoun, O., Spigno, G., \& Madani, K. (2013). Valorization of Citrus limon residues for the recovery of antioxidants: Evaluation and optimization of microwave and ultrasound application to solvent extraction. Industrial Crops and Products, 50, 77-87.

Dai, J., \& Mumper, R.J. (2010). Plant phenolics: extraction, analysis and their antioxidant and anticancer properties. Molecules, 15, 7313-7352.

D'Alessandro, L.G., Dimitrov, K., Vauchel, P., \& Nikov, I. (2014). Kinetics of ultrasound assisted extraction of anthocyanins from Aronia melanocarpa (black chokeberry) wastes. Chemical Engineering Research and Design, 92, 1818-1826.

FAO, 2016. Intergovernmental Group on Citrus Fruits. A Subsidiary Body of the FAO Committee on Commodity Problems (CCP) Rome. http://www.fao.org/3/a-i5558e.pdf, 2016 Accessed 03.01.2017.

Garcia-Castello, E.M., Rodriguez-Lopez, A.D., Mayor, L., Ballesteros, R., Conidi, C., \& Cassano, A. (2015). Optimization of conventional and ultrasound assisted extraction of flavonoids from grapefruit (Citrus paradisi L.) solid wastes. LWT - Food Science and Technology, 64, 1114-1122.

Garg, A., Garg, S., Zaneveld, L.J., \& Singla, A.K. (2001). Chemistry and pharmacology of the Citrus bioflavonoid hesperidin. Phytotherapy Research, 15, 655-669. 
Hani, N.M., Torkamani, A.E., Zainul Abidin, S., Mahmood, W.A.K., \& Juliano, P. (2017). The effects of ultrasound assisted extraction on antioxidative activity of polyphenolics obtained from Momordica charantia fruit using response surface approach. Food Bioscience, 17, 7-16. Khan, M.K., Abert-Vian, M., Fabiano-Tixier, A.S., Dangles, O., \& Chemat, F. (2010). Ultrasound-assisted extraction of polyphenols (flavanone glycosides) from orange (Citrus sinensis L.) peel. Food Chemistry, 119, 851-858.

Lee, Y.H., Charles, A.L., Kung, H.F., Ho, C.T., \& Huang, T.C. (2010). Extraction of nobiletin and tangeretin from Citrus depressa Hayata by supercritical carbon dioxide with ethanol as modifier. Industrial Crops and Products, 31, 59-64.

Li, J., Zhang, P., Chen, J., Yao, Q., \& Jiang, Y. (2009). Cellular wall metabolism in citrus fruit pericarp and its relation to creasing fruit rate. Scientia Horticulturae, 122, 45-50.

Lou, S.N., Lai, Y.C., Hsu, Y.S., \& Ho, C.T. (2016). Phenolic content, antioxidant activity and effective compounds of kumquat extracted by different solvents. Food Chemistry, 197, Part A, $1-6$.

Ma, X., Zhang, L., Wang, W., Zou, M., Ding, T., Ye, X., \& Liu, D. (2016). Synergistic Effect and Mechanisms of Combining Ultrasound and Pectinase on Pectin Hydrolysis. Food and Bioprocess Technology, 9, 1249-1257.

Ma, Y.Q., Chen, J.C., Liu, D.H., \& Ye, X.Q. (2009). Simultaneous extraction of phenolic compounds of citrus peel extracts: Effect of ultrasound. Ultrasonics Sonochemistry, 16, 57-62. Ma, Y.Q., Ye, X.Q., Fang, Z.X., Chen, J.C., Xu, G.H., \& Liu, D.H. (2008a). Phenolic compounds and antioxidant activity of extracts from ultrasonic treatment of Satsuma Mandarin (Citrus unshiu Marc.) peels. Journal of Agricultural and Food Chemistry, 56, 5682-5690.

Ma, Y., Ye, X., Hao, Y., Xu, G., Xu, G., \& Liu, D. (2008b). Ultrasound-assisted extraction of hesperidin from Penggan (Citrus reticulata) peel. Ultrasonics Sonochemistry, 15, 227-232.

Ma, Y.Q., Chen, J.C., Liu, D.H., \& Ye, X.Q. (2008c). Effect of ultrasonic treatment on the total phenolic and antioxidant activity of extracts from citrus peel. Journal of Food Science, 73, T115-T120.

Nguyen, T.B.T., Ketsa, S., \& Van Doorn, W.G. (2003). Relationship between browning and the activities of polyphenoloxidase and phenylalanine ammonia lyase in banana peel during low temperature storage. Postharvest Biology and Technology, 30, 187-193.

Ortuño, A., Báidez, A., Gómez, P., Arcas, M.C., Porras, I., García-Lidón, A., \& Río, J.A.D. (2006). Citrus paradisi and Citrus sinensis flavonoids: Their influence in the defence mechanism against Penicillium digitatum. Food Chemistry, 98, 351-358.

Papoutsis, K., Pristijono, P., Golding, J.B., Stathopoulos, C.E., Bowyer, M.C., Scarlett, C.J., \& Vuong, Q.V. (2017). Effect of vacuum-drying, hot air-drying and freeze-drying on polyphenols and antioxidant capacity of lemon (Citrus limon) pomace aqueous extracts. International Journal of Food Science \& Technology, 52, 880-887.

Papoutsis, K., Pristijono, P., Golding, J.B., Stathopoulos, C.E., Scarlett, C.J., Bowyer, M.C., \& Vuong, Q.V. (2016). Impact of different solvents on the recovery of bioactive compounds and antioxidant properties from lemon (Citrus limon L.) pomace waste. Food Science and Biotechnology, 25, 971-977.

Putnik, P., Bursać Kovačević, D., Režek Jambrak, A., Barba, F., Cravotto, G., Binello, A., Lorenzo, J., \& Shpigelman, A. (2017). Innovative "Green" and Novel Strategies for the Extraction of Bioactive Added Value Compounds from Citrus Wastes-A Review. Molecules, 22, 680. doi:10.3390/molecules22050680

Roselló-Soto, E., Galanakis, C.M., Brnčić, M., Orlien, V., Trujillo, F.J., Mawson, R., Knoerzer, K., Tiwari, B.K., \& Barba, F.J. (2015). Clean recovery of antioxidant compounds from plant foods, by-products and algae assisted by ultrasounds processing. Modeling approaches to optimize processing conditions. Trends in Food Science \& Technology, 42, 134-149. 
Shahidi, F., \& Yeo, J.D. (2016). Insoluble-Bound Phenolics in Food. Molecules, 21, 1216. doi:10.3390/molecules21091216

443 Sharma, K., Mahato, N., Cho, M.H., \& Lee, Y.R. (2017). Converting citrus wastes into valueadded products: Economic and environmently friendly approaches. Nutrition, 34, 29-46. Shetty, S.B., Mahin-Syed-Ismail, P., Varghese, S., Thomas-George, B., Kandathil-Thajuraj, P., Baby, D., Haleem, S., Sreedhar, S., \& Devang-Divakar, D. (2016). Antimicrobial effects of Citrus sinensis peel extracts against dental caries bacteria: An in vitro study. Journal of Clinical 448 and Experimental Dentistry, 8, e71-e77.

449 Škerget, M., Kotnik, P., Hadolin, M., Hraš, A.R., Simonič, M., \& Knez, Ž. (2005). Phenols, 450 proanthocyanidins, flavones and flavonols in some plant materials and their antioxidant 451 activities. Food Chemistry, 89, 191-198.

452 Stamatopoulos, K., Chatzilazarou, A., \& Katsoyannos, E. (2013). Optimization of Multistage 453 Extraction of Olive Leaves for Recovery of Phenolic Compounds at Moderated Temperatures 454 and Short Extraction Times. Foods, 3, 66. doi:10.3390/foods3010066. Thaipong, K., Boonprakob, U., Crosby, K., Cisneros-Zevallos, L., \& Hawkins Byrne, D. (2006). Comparison of ABTS, DPPH, FRAP, and ORAC assays for estimating antioxidant activity from guava fruit extracts. Journal of Food Composition and Analysis, 19, 669-675. Wang, Y.C., Chuang, Y.C., \& Ku, Y.H. (2007). Quantitation of bioactive compounds in citrus fruits cultivated in Taiwan. Food Chemistry, 102, 1163-1171. in mulberry and their scavenging effects on superoxide radicals. Food Chemistry, 64, 555-559. 


\section{Tables}

Table 1. Effect of different ultrasonic extraction parameters on the total phenolic content (TPC), and total flavonoid content (TF). Data are expressed as mean \pm standard deviation $(n=3)$.

\begin{tabular}{|c|c|c|c|c|c|c|c|c|c|c|c|}
\hline \multicolumn{3}{|c|}{$\begin{array}{c}\text { Effect of } \\
\text { Particle size }\end{array}$} & \multicolumn{3}{|c|}{$\begin{array}{c}\text { Effect of } \\
\text { Extraction time }\end{array}$} & \multicolumn{3}{|c|}{$\begin{array}{c}\text { Effect of } \\
\text { Extraction temperature }\end{array}$} & \multicolumn{3}{|c|}{$\begin{array}{c}\text { Effect of } \\
\text { Ultrasonic power }\end{array}$} \\
\hline Size & TPC & $\mathrm{TF}$ & Time & TPC & $\mathrm{TF}$ & Temperature & TPC & TF & Power & TPC & $\mathrm{TF}$ \\
\hline $\mathrm{mm}$ & mg GAE/g & $\mathrm{mg} \mathrm{CE} / \mathrm{g}$ & $\min$ & mg GAE/g & $\mathrm{mg} \mathrm{CE} / \mathrm{g}$ & ${ }^{\circ} \mathrm{C}$ & mg GAE/g & $\mathrm{mg} \mathrm{CE} / \mathrm{g}$ & $\mathrm{W}$ & mg GAE/g & $\mathrm{mg} \mathrm{CE} / \mathrm{g}$ \\
\hline 1.40 & $15.76 \pm 0.18^{a^{*}}$ & $4.65 \pm 0.14^{\mathrm{a}}$ & 10 & $15.72 \pm 0.20^{\mathrm{a}}$ & $4.55 \pm 0.10^{\mathrm{a}}$ & Ambient & $16.38 \pm 0.23^{b}$ & $4.64 \pm 0.03^{b}$ & 150 & $15.48 \pm 0.13^{\mathrm{a}}$ & $4.56 \pm 0.13^{\mathrm{a}}$ \\
\hline 2.00 & $14.76 \pm 0.03^{\mathrm{b}}$ & $4.40 \pm 0.04^{\mathrm{ab}}$ & 20 & $15.88 \pm 0.62^{\mathrm{a}}$ & $4.56 \pm 0.16^{\mathrm{a}}$ & 30 & $16.32 \pm 0.11^{b}$ & $4.62 \pm 0.01^{\mathrm{b}}$ & 200 & $15.24 \pm 0.62^{\mathrm{a}}$ & $4.56 \pm 0.27^{\mathrm{a}}$ \\
\hline \multirow[t]{4}{*}{2.80} & $14.37 \pm 0.25^{\mathrm{b}}$ & $4.10 \pm 0.01^{\mathrm{b}}$ & 30 & $15.89 \pm 0.10^{\mathrm{a}}$ & $4.82 \pm 0.07^{\mathrm{a}}$ & 40 & $16.75 \pm 0.06^{\mathrm{ab}}$ & $4.74 \pm 0.03^{\mathrm{ab}}$ & 250 & $15.77 \pm 0.21^{\mathrm{a}}$ & $4.66 \pm 0.09^{\mathrm{a}}$ \\
\hline & & & 40 & $16.59 \pm 0.39^{a}$ & $4.81 \pm 0.15^{\mathrm{a}}$ & 50 & $17.24 \pm 0.15^{\mathrm{a}}$ & $4.84 \pm 0.08^{\mathrm{a}}$ & & & \\
\hline & & & 50 & $16.21 \pm 0.61^{\mathrm{a}}$ & $4.74 \pm 0.01^{\mathrm{a}}$ & & & & & & \\
\hline & & & 60 & $16.13 \pm 0.16^{\mathrm{a}}$ & $4.73 \pm 0.10^{\mathrm{a}}$ & & & & & & \\
\hline $\mathrm{CV}^{* *}$ & $1.59 \%$ & $2.79 \%$ & & $2.52 \%$ & $2.37 \%$ & & $1.29 \%$ & $1.34 \%$ & & $3.45 \%$ & $5.33 \%$ \\
\hline
\end{tabular}

*Values followed by different letters within the same column are significantly different at $P<0.05$, according to ANOVA and Tukey's test.

** Coefficient of variation $(\mathrm{CV})$. 
Table 2. Effect of different ultrasonic extraction parameters on the antioxidant capacity measured by CUPRAC and DPPH assays. Data are expressed as mean \pm standard deviation $(n=3)$.

\begin{tabular}{|c|c|c|c|c|c|c|c|c|c|c|c|}
\hline \multicolumn{3}{|c|}{$\begin{array}{c}\text { Effect of } \\
\text { Particle size }\end{array}$} & \multicolumn{3}{|c|}{$\begin{array}{c}\text { Effect of } \\
\text { Extraction time }\end{array}$} & \multicolumn{3}{|c|}{$\begin{array}{c}\text { Effect of } \\
\text { Extraction temperature }\end{array}$} & \multicolumn{3}{|c|}{$\begin{array}{c}\text { Effect of } \\
\text { Ultrasonic power }\end{array}$} \\
\hline Size & CUPRAC & DPPH & Time & CUPRAC & DPPH & Temperature & CUPRAC & DPPH & Power & CUPRAC & DPPH \\
\hline $\mathrm{mm}$ & $\mathrm{mg} \mathrm{TE} / \mathrm{g}$ & $\mathrm{mg} \mathrm{TE} / \mathrm{g}$ & $\min$ & $\mathrm{mg} \mathrm{TE} / \mathrm{g}$ & $\mathrm{mg} \mathrm{TE} / \mathrm{g}$ & ${ }^{\circ} \mathrm{C}$ & $\mathrm{mg} \mathrm{TE} / \mathrm{g}$ & $\mathrm{mg} \mathrm{TE} / \mathrm{g}$ & $\mathrm{W}$ & $\mathrm{mg} \mathrm{TE} / \mathrm{g}$ & $\mathrm{mg} \mathrm{TE} / \mathrm{g}$ \\
\hline 1.40 & $32.91 \pm 1.44^{\mathrm{a}^{*}}$ & $0.129 \pm 0.002^{\mathrm{a}}$ & 10 & $31.97 \pm 0.03^{\mathrm{a}}$ & $0.113 \pm 0.006^{\mathrm{a}}$ & Ambient & $33.49 \pm 0.37^{b}$ & $0.125 \pm 0.003^{\mathrm{a}}$ & 150 & $32.38 \pm 0.84^{\mathrm{a}}$ & $0.120 \pm 0.001^{\mathrm{a}}$ \\
\hline 2.00 & $29.87 \pm 0.04^{\mathrm{ab}}$ & $0.122 \pm 0.001^{\mathrm{b}}$ & 20 & $32.37 \pm 0.91^{\mathrm{a}}$ & $0.116 \pm 0.005^{a}$ & 30 & $33.76 \pm 0.56^{\mathrm{b}}$ & $0.125 \pm 0.001^{\mathrm{a}}$ & 200 & $32.44 \pm 1.30^{\mathrm{a}}$ & $0.117 \pm 0.003^{a}$ \\
\hline \multirow[t]{4}{*}{2.80} & $28.75 \pm 1.00^{\mathrm{b}}$ & $0.118 \pm 0.003^{b}$ & 30 & $32.76 \pm 0.04^{\mathrm{a}}$ & $0.122 \pm 0.016^{\mathrm{a}}$ & 40 & $34.40 \pm 0.63^{\mathrm{ab}}$ & $0.128 \pm 0.001^{\mathrm{a}}$ & 250 & $33.61 \pm 0.42^{\mathrm{a}}$ & $0.117 \pm 0.007^{\mathrm{a}}$ \\
\hline & & & 40 & $33.47 \pm 0.74^{\mathrm{a}}$ & $0.111 \pm 0.010^{\mathrm{a}}$ & 50 & $36.29 \pm 0.67^{\mathrm{a}}$ & $0.128 \pm 0.002^{\mathrm{a}}$ & & & \\
\hline & & & 50 & $32.66 \pm 0.54^{\mathrm{a}}$ & $0.104 \pm 0.009^{\mathrm{a}}$ & & & & & & \\
\hline & & & 60 & $33.52 \pm 0.82^{a}$ & $0.112 \pm 0.007^{\mathrm{a}}$ & & & & & & \\
\hline $\mathrm{CV}^{* *}$ & $4.42 \%$ & $2.53 \%$ & & $1.91 \%$ & $8.58 \%$ & & $2.17 \%$ & $1.73 \%$ & & $3.72 \%$ & $5.31 \%$ \\
\hline
\end{tabular}

\footnotetext{
*Values followed by different letters within the same column are significantly different at $P<0.05$, according to ANOVA and Tukey's test.
}

** Coefficient of variation $(\mathrm{CV})$. 


\section{Figures}

Fig. 1. Experimental design of the experiment.

TPC: Total phenolic content; TF: Total flavonoid content.

Fig. 2. Effect of particle size of sample on phenolic acids and hesperidin (A, B); effect of extraction time on phenolic acids and hesperidin (C, D); effect of extraction temperature on phenolic acids and hesperidin (E, F); effect of ultrasonic power on phenolic acids and hesperidin $(\mathrm{G}, \mathrm{H})$. Data are expressed as mean \pm standard deviation $(n=3)$. Different letters above histogram bars indicate significant differences between means according to ANOVA and Tukey's test at $P<0.05$.

Fig. 3. Images of the morphology of different lemon pomace particle sizes using scanning electron microscopy (SEM): $1.40 \mathrm{~mm}$ (a); $2.00 \mathrm{~mm}$ (b) and $2.80 \mathrm{~mm}$ (c). 